\title{
Diciocho aÑos Del ObSERVATORIO de la IMAGEN DE LAS MUJERES
}

\author{
María Jesús Ortiz Gómez \\ mariajesus.ortizgomez@inmujer.es \\ Instituto de la Mujer
}

Miguel Ángel del Arco Bravo

miguelangel.arco@uc3m.es

Universidad Carlos III

Recibido: 28-02-2012

Aceptado: 20-03-2012

\section{Resumen}

La publicidad utiliza estereotipos para facilitar la comprensión y aceptación de sus mensajes. Pero el uso de estereotipos de género contribuye a perpetuar la discriminación hacia las mujeres, ya que proceden de un sistema patriarcal histórico que atribuye a cada sexo funciones específicas, que en el caso de las mujeres se reducen al ámbito de la reproducción. La multiplicación de impactos reiterando estos estereotipos influye en la mentalidad social que, a pesar de los cambios legales, sigue asumiendo como naturales esas diferencias. Las políticas públicas están dirigidas a suprimir las barreras que impiden la igualdad real. El Instituto de la Mujer, a través del Observatorio de la Imagen, persigue transformar esas pautas de comunicación hacia un modelo que respete la dignidad y los derechos de las mujeres.

Palabras clave: Derechos de las mujeres, discriminación, estereotipos de género, igualdad real, Instituto de la Mujer, Observatorio de la Imagen, publicidad.

\begin{abstract}
Advertising uses stereotypes to make their messages easier to understand and accept. But the use of gender stereotypes contributes to perpetuate women discrimination, because they come from a historical patriarchal system that attributes to each sex specific roles, which in the case of women are limited to the reproduction field. The numerous impacts repeating these stereotypes influence the social mentality and, in spite of the legal changes, people continue to accept as natural those differences. The aim of public policies is to eradicate the obstacles for a real equality. The Women Institute, through the Image Observatory, intends to modify these forms of communication to other model that respect the rights and dignity of women.
\end{abstract}

Keywords: Women rights, discrimination, gender stereotypes, real equality, Women Institute, Image Observatory, advertising. 


\section{Introducción. La discriminación de las mujeres en la publicidad}

La publicidad, que inunda nuestras vidas a través de múltiples cauces, que reitera sus mensajes con insistencia, que aparece en cada paso y a cada minuto de nuestro quehacer diario, no trata bien a las mujeres. Persigue generar un comportamiento inmediato del público al que se dirige, pero simultáneamente va construyendo una realidad alternativa que consigue desfigurar la percepción de lo que nos rodea. Parte de esa distorsión es la imagen que proyecta de las mujeres: sus actividades, sus cualidades, sus aspiraciones, sus capacidades o sus posibilidades aparecen lastradas por estereotipos de género, que constituyen la inspiración creativa de la mayoría de las campañas.

La profesora García Nieto define la publicidad como "una forma de comunicación persuasiva de carácter comercial, con el objetivo de cambiar las creencias, actitudes y conductas de los públicos, para conseguir la compra, la contratación o el consumo de los productos o servicios anunciados" (Nieto y Devesa, 2008: 9).

Esta definición, si bien se refiere a la publicidad estrictamente comercial, dejando fuera las campañas institucionales cuyo objetivo no es la venta sino lograr un beneficio social, recoge dos de sus principales características: la primera, que no pretende convencer sino persuadir y, la segunda, que promueve cambios en las actitudes y conductas. Pero es necesario destacar que esos cambios no se limitan a las pautas de consumo sino que acaban influyendo en todos los comportamientos.

El recurso al marketing aspiracional ${ }^{1}$ y las campañas de imagen de marca ofrecen modelos idealizados que constituyen una referencia de lo que es socialmente aceptado y llevan a asumirlos e incorporarlos al acerbo personal sin cuestionarlos. De esta forma, la publicidad, junto con los medios de comunicación, se ha convertido en un potente factor de socialización.

En este contexto se puede afirmar que la representación de la imagen de las mujeres tiene una incidencia directa sobre el avance -o retroceso- de la igualdad real. Cómo son tratadas las mujeres en la publicidad y los medios ha sido una cuestión estrechamente unida a la lucha por sus plenos derechos, desde hace décadas, y se refleja en las múltiples investigaciones y análisis realizados sobre la materia.

Una cuestión que ha sido incluida en diferentes textos normativos sobre igualdad de género, tanto nacionales como internacionales. Son también numerosas las actuaciones llevadas a cabo, desde las instituciones y las organizaciones feministas, para incidir en la transmisión de una imagen digna y no estereotipada de las mujeres.

La Plataforma para la Acción de la IV Conferencia Mundial sobre la Mujer, celebrada en Beijing en 1995, entre los 12 objetivos estratégicos propuestos para eliminar los obstáculos que dificultan la igualdad de género, dedica el $8^{\circ}$ a los medios de comunicación.

\footnotetext{
${ }^{1}$ Término publicitario para denominar las campañas que van dirigidas a satisfacer no las necesidades sino los deseos del/a potencial consumidor/a (deseos que nos acercan a lo que aspiramos por encima de lo que somos).
} 
En el apartado "J", entre otras consideraciones, se aboga por "suprimir la proyección constante de imágenes negativas y degradantes de la mujer en los medios de comunicación, sean electrónicos, impresos, visuales o sonoros", y alude específicamente a los programas que insisten en presentar a la mujer en sus papeles tradicionales. Propone instaurar mecanismos de autorregulación e invita a los gobiernos a poner en marcha distintas medidas, entre las que cabe citar:

- Alentar a los medios de difusión a que se abstengan de presentar a la mujer como un ser inferior y de explotarla como objeto sexual y bien de consumo (...)

- Fomentar la idea de que los estereotipos sexistas que se presentan en los medios de difusión son discriminatorios para la mujer, degradantes y ofensivos.

En el ámbito de la Unión Europea han sido diversas las normativas aprobadas con el ánimo de transformar esa representación negativa de las mujeres por otra igualitaria y respetuosa con sus derechos. Sin ánimo de ser exhaustivos, cabe mencionar las siguientes resoluciones: "Presentación y posición de la mujer en los medios de comunicación de masas" (Parlamento Europeo, 1987), "Tratamiento de la imagen de las mujeres y de los hombres en la publicidad y los medios de comunicación" (Parlamento Europeo, 1995), "La discriminación de la mujer en la publicidad" (Parlamento Europeo, 1997), "El impacto del marketing y la publicidad en la igualdad entre mujeres y hombres" (Parlamento Europeo, 2009).

\section{Regulación versus autorregulación}

En España hay que citar expresamente las dos leyes orgánicas aprobadas en la legislatura 2004-2007: La LO 1/2004, de Medidas de Protección Integral contra la Violencia de Género, y la LO 3/2007, para la Igualdad Efectiva entre Mujeres y Hombres. Ambas dedican parte de su articulado a los medios de comunicación y la publicidad. La primera tiene especial importancia porque, por un lado, pone de manifiesto que el tratamiento discriminatorio de las mujeres en la publicidad coadyuva a la violencia de género y porque, por otro, modifica la Ley General de Publicidad de 1988 ampliando el criterio de lo que se considera publicidad ilícita:

“[...] los anuncios que presenten a las mujeres de forma vejatoria o discriminatoria, bien utilizando particular y directamente su cuerpo o partes del mismo como mero objeto desvinculado del producto que se pretende promocionar, bien su imagen asociada a comportamientos estereotipados [...]" (España, 2009: 112053).

La Ley de Igualdad hace especial hincapié en los de titularidad pública, detallando explícitamente en qué aspectos están obligados a promover la igualdad. Pero, al igual que la 
Ley de Violencia de Género, se apuesta básicamente por la autorregulación, especialmente para los medios privados.

La aprobación de estas dos normas ha tenido un efecto pedagógico al incrementar, en el sector de la comunicación, el conocimiento y la sensibilidad sobre la importancia que tiene para la igualdad el respeto a la imagen de las mujeres. Sin embargo, lamentablemente, esto no se ha traducido en un cambio significativo a la hora de abordar los contenidos.

Pese a la adopción de algunas iniciativas por parte de los poderes públicos, los medios de comunicación no han dado ningún paso hacia la autorregulación, ni colectiva ni individualmente, y no han ido más allá de asumir algunas recomendaciones en el caso del tratamiento informativo de la violencia de género y una cierta prudencia ante la representación femenina más degradante, especialmente porque empieza a tener una clara contestación social. Los estereotipos, más o menos vejatorios, siguen inundando las pantallas de televisión, las emisoras de radio y las páginas de prensa, a las que se une Internet, donde anida un machismo especialmente agresivo del que más adelante se exponen algunos ejemplos.

Tampoco la publicidad escapa al uso de los estereotipos, aunque en este caso sí se ha producido un efecto. Las empresas anunciantes son muy sensibles a su imagen social, ya que de ella depende su cuota de mercado, de ahí que desde el año 1996 cuente con un eficiente órgano de autorregulación, (Autocontrol). Esta asociación actúa de dos formas: atender reclamaciones, que se resuelven por un jurado independiente, y prestar un servicio de asesoramiento previo a la emisión de las campañas (Copy advice).

Analizando 51 resoluciones del jurado sobre campañas sexistas se percibe un claro cambio entre las anteriores (28) y las posteriores (23) al año 2004. Que la Ley de Violencia de Género establezca, de forma explícita, que es ilícito el uso del cuerpo femenino sin relación con el producto, cambió la forma de valorar las campañas que recurren al desnudo parcial o total de las mujeres. Hasta entonces la mayoría se juzgaban bajo el criterio de buen gusto ${ }^{2}$, es decir, que hicieran referencias explícitas al sexo y se estimaban si se consideraban procaces o traspasaban los límites del decoro social.

Ninguna referencia a que la mujer fuera utilizada como un objeto. A partir de la aprobación de la ley se produce un cambio, tanto en las denuncias como en las resoluciones: El desnudo femenino empieza a dejar de relacionarse con el buen gusto y se trata más como discriminación ${ }^{3}$, a la vez que se incrementan las estimaciones de las reclamaciones por parte del jurado. La evolución puede verse en los siguientes gráficos (referidos a las 51 resoluciones mencionadas):

\footnotetext{
${ }^{2}$ Norma 8 del Código de Conducta Publicitaria, "Respeto al buen gusto: La publicidad no deberá incluir contenidos que atenten contra los criterios imperantes del buen gusto y del decoro social, así como contra las buenas costumbres" (Autocontrol, 1996: 04).

${ }^{3}$ Norma 10 del Código de Conducta Publicitaria, "Publicidad discriminatoria: La publicidad no sugerirá circunstancias de discriminación ya sea por razón de raza, nacionalidad, religión, sexo u orientación sexual, ni atentará contra la dignidad de la persona. En particular, se evitarán aquellos anuncios que puedan resultar vejatorios o discriminatorios para la mujer" (Autocontrol, 1996: 04).
} 
Graficol: Porcentaje de resoluciones estimadas y desestimadas sobre el total de emitidas

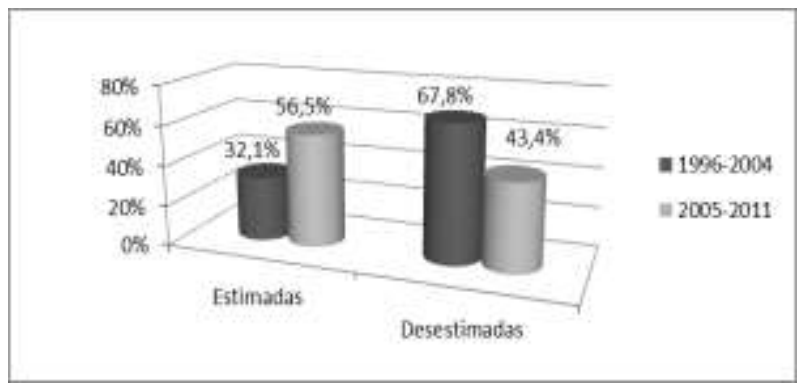

Elaboración propia

Grafico 2: Porcemtaje de resoluciones referidas a los criterios de "Buen gusto" y de "Discriminación"

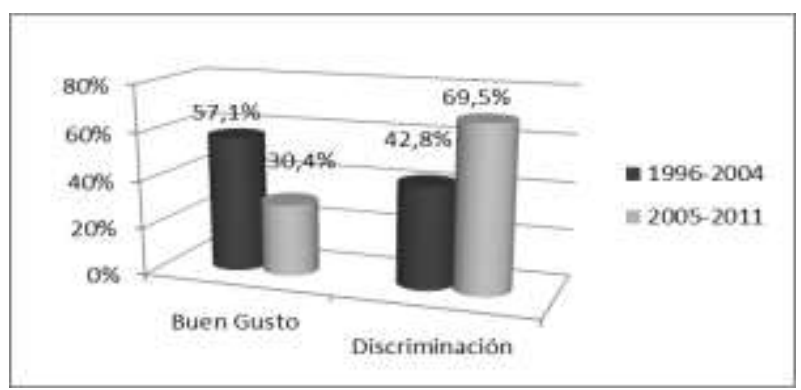

Elaboración propia

Grafico 3: Porcentaje de resoluciones estimadas y desestimadas del criterio de "Buen gusto"

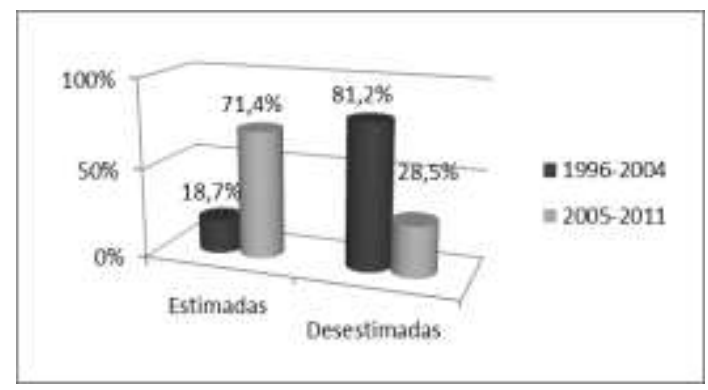

Elaboración propia

Se observa, por tanto, que no solo aumentan las estimaciones, sino que muchas de las quejas que antes se tramitaban y resolvían como cuestión de buen gusto empiezan a entenderse como campañas discriminatorias y, a partir de la aprobación de la Ley de Violencia de Género, el argumento del recurso al cuerpo/desnudo femenino como reclamo sin relación con el producto es el principal criterio de estimación utilizado por el jurado. 


\section{Estereotipos discriminatorios}

No ha sido tan fácil la aplicación de la nueva redacción del artículo tercero de la Ley General de Publicidad, en lo referente a la dignidad de las mujeres y los comportamientos estereotipados. El análisis de las resoluciones del Jurado de Autocontrol permite comprobar que aún es necesario extender, tanto entre profesionales como en el público, una enunciación más precisa de lo que es discriminatorio y sexista.

La mayor dificultad radica en el uso de estereotipos, un recurso necesario para comunicar fácilmente y con brevedad, dos requisitos imprescindibles para los medios de comunicación. Los estereotipos, según la profesora Felicidad Loscertales (Núñez Domínguez y Loscertales Abril, 2009: 25), son una "generalización en las atribuciones sociales sobre una persona por causa de su pertenencia a un grupo determinado".

La autora explica que las distintas culturas han elaborado unas definiciones muy claras acerca de las mujeres y de los hombres "lo que son y lo que deben hacer; qué conductas se esperan de cada uno de estos sexos y cuáles les están vetadas" y que una consecuencia de este proceso es que los propios grupos estereotipados se autoatribuyen las características del grupo asignado. Citando a los autores americanos Williams \& Best (1990) distingue entre:

- estereotipos de rol: aquellos que determinan los roles adscritos a cada grupo y cuáles son las cosas permitidas y prohibidas, y

- estereotipos de rasgo: los que asignan determinadas características psicológicas o rasgos de personalidad a hombres y mujeres, por el hecho de serlo.

Los estereotipos tienen como causa y efecto considerar que los roles y los rasgos de género son algo "natural", un determinante biológico. Si además son una fuente inagotable de recursos para los medios de comunicación y la publicidad, se crea un círculo vicioso de desigualdad difícil de romper: El machismo social alimenta el machismo en la comunicación y este perpetúa y arraiga aún más el sexismo y la discriminación en nuestra sociedad, constituyendo un gravísimo freno a los logros de las políticas públicas dirigidas a transformar las actitudes y comportamientos en favor de la igualdad.

\section{Función del Observatorio de la Imagen de las Mujeres}

En el año 1994, en lo que constituye una experiencia pionera, el Instituto de la Mujer pone en marcha un instrumento dirigido a intentar romper ese círculo vicioso: el Observatorio de la Publicidad Sexista, que en 2005 pasó a denominarse Observatorio de la Imagen de las Mujeres (OIM) con el fin de reflejar mejor sus objetivos y su trabajo. Su principal valor es que se configura como una herramienta de participación ciudadana que multiplica su capacidad de 
observación y contribuye a incrementar la sensibilización social contra el reflejo mediático de la ideología del patriarcado. El Observatorio tiene un doble objetivo:

- Advertir del incumplimiento de la legalidad vigente y promover actuaciones contra las campañas ilícitas y

- Fomentar la sensibilización de los distintos sectores profesionales e incrementar la percepción crítica de la población hacia los contenidos sexistas.

Las funciones encomendadas al Observatorio, que se recogen en la página web del organismo (www.inmujer.es) y en los informes anuales sobre su actividad, son:

$\checkmark$ Detección de contenidos sexistas, mediante seguimiento de oficio y a través de las quejas remitidas por particulares, entidades o colectivos.

$\checkmark$ Análisis y valoración de los contenidos detectados o denunciados para determinar el procedimiento a seguir en cada caso, principalmente efectuar un requerimiento de cese o modificación o emitir recomendaciones.

$\checkmark$ Clasificación de los casos con el fin de obtener una visión general del tratamiento de la imagen de las mujeres, que se difunde principalmente a través del informe anual.

$\checkmark$ Colaborar en la formación y sensibilización mediante la participación en actividades y encuentros, especialmente en el ámbito educativo, asociativo e institucional.

El trabajo realizado en el Observatorio, analizando numerosos contenidos tanto publicitarios como no publicitarios, ha permitido ir definiendo distintas manifestaciones de sexismo a partir de las cuales se ha establecido una clasificación $(O I M, 2008)$ que permite una mayor concreción sobre qué elementos pueden constituir publicidad ilícita por fomentar los estereotipos o atentar contra la dignidad de las mujeres. Clasificación que puede servir de referencia tanto a profesionales como al público:

a) Frivolizar o justificar actitudes que supongan cualquier forma de violencia contra las mujeres.

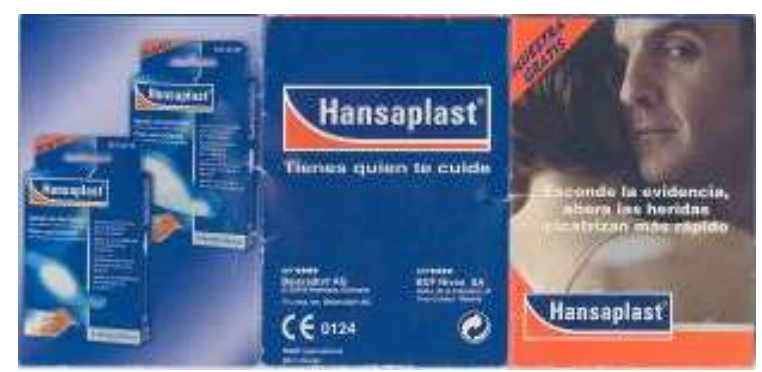

Fuente: (OIM, 2008: 35)
En este anuncio de tiritas Hansaplast se lee: "Esconde la evidencia, ahora las heridas cicatrizan más rápido". Una evidencia es la prueba de un acto delictivo lo que, unido a la mirada de complicidad del varón, no puede interpretarse más que como una clara alusión a la violencia de género. 
b) Situar a las mujeres en posiciones de subordinación o inferioridad.

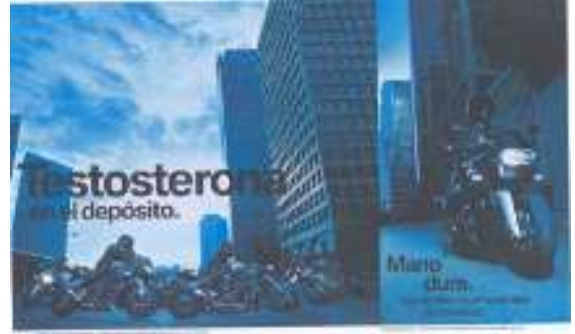

Fuente: (OIM, 2008: 34)
En esta imagen, perteneciente a un folleto de motos BMW dirigido a varones, se vincula la virilidad (testosterona en el depósito) con la mano dura y la autoridad (alguien tiene que hacer valer su autoridad), lo que sitúa a las mujeres en una posición de subordinación a dicha autoridad.

c) Menospreciar o ridiculizar las actividades o valores atribuidos a las mujeres.

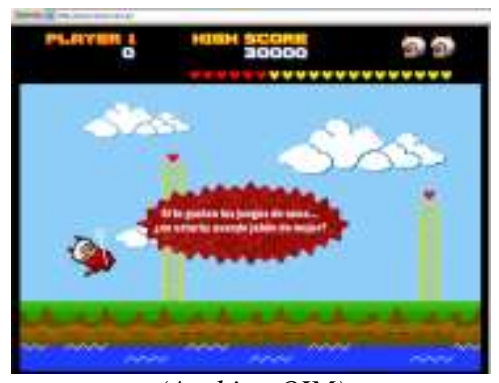

(Archivo OIM)

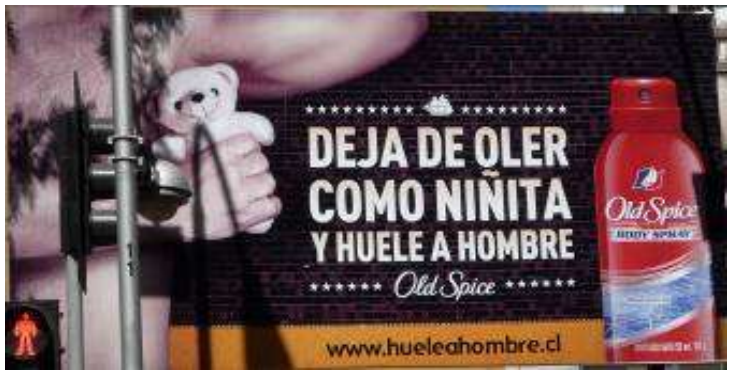

(Archivo OIM)

Ambos anuncios, de jabón Axe y desodorante Old Spice, recurren a una mirada despectiva sobre lo femenino, contraponiendo en el segundo lo femenino, simbolizado en el oso de peluche (ternura, infantilismo, ingenuidad...) con un el vigor y la firmeza masculinas, representado por el brazo musculoso.

d) Ridiculizar, infravalorar o presentar de forma vejatoria a las mujeres en una actividad profesional (habitual en profesiones feminizadas como maestras, camareras, azafatas o enfermeras).

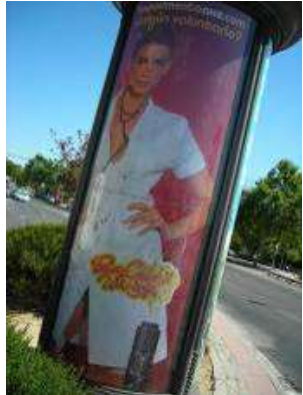

Fuente: (OIM, 2007: 17

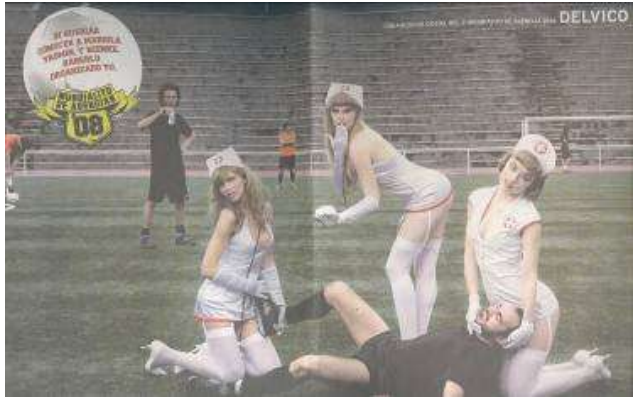

Fuente: (OIM, 2008: 17) 
La profesión en estos dos ejemplos, desodorante AXE y campeonato de fútbol "Mundialito de agencias", no es más que un complemento fetichista de la utilización de las mujeres como objeto sexual. Se ignora la profesionalidad femenina y se convierte su actividad laboral en un juego erótico.

e) Reducir a las mujeres a un mero objeto sexual, pasivo y al servicio de los deseos del hombre. A veces con el agravante de recurrir a la sexualización de niñas.

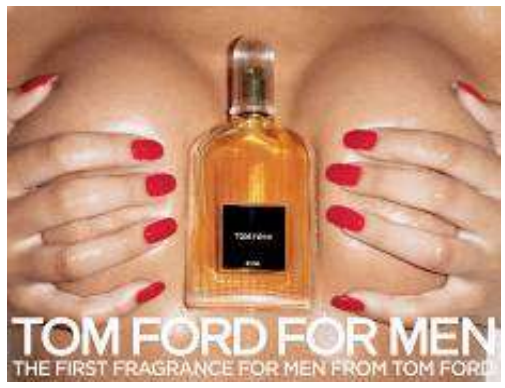

(Fuentes: Archivo OIM

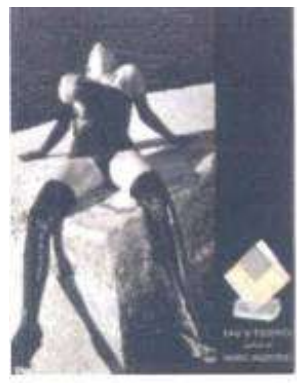

(Archivo OIM)

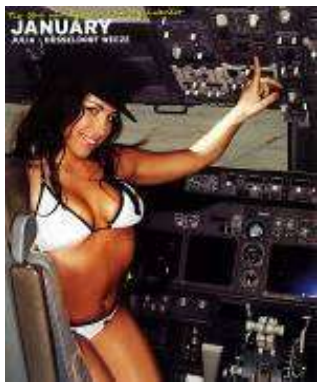

OIM, 2007: 24)

La postura o la mirada son algunos de los aspectos con los que se juega para incrementar el carácter sugerente o de ofrecimiento. La primera es un ejemplo claro de cosificación sexual en el que la identidad femenina queda reducida a unos senos.

f) Exhibir imágenes del cuerpo femenino, o partes del mismo, como un reclamo para atraer la atención y sin relación con lo anunciado.

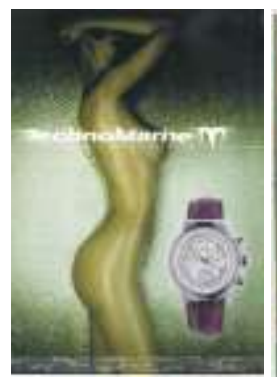

Fuentes: (Archivo OIM)

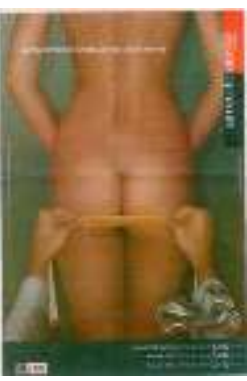

(OIM, 2006: 15)

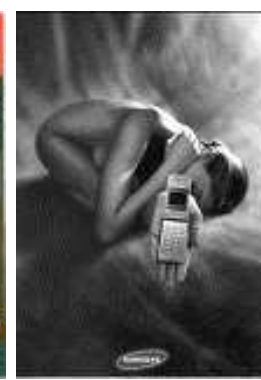

(Archivo OIM)

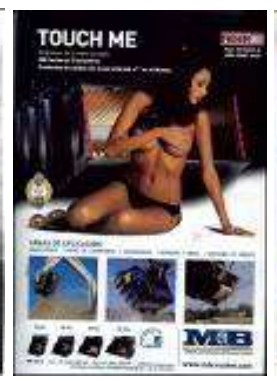

(OIM, 2009: 14)

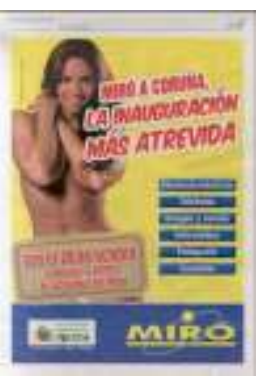

(Archivo OIM)

Son innumerables las campañas que recurren al cuerpo y al desnudo femenino como un reclamo. Desde grandes marcas, como en este caso Samsung o Miró, a publicidad de pequeños anunciantes o de productos especializados, como el de las excavadoras MB. A través de una creatividad de alta calidad artística o con un tratamiento ramplón. A diferencia de los 
casos anteriores, la oferta erótica no es tan explícita, pero la despersonalización es la misma, sobre todo mediante el ocultamiento del rostro.

g) Fomentar un modelo de belleza femenino basado en la juventud, delgadez o perfección corporal, de acuerdo con cánones poco reales, que puedan inducir a comportamientos lesivos para la salud de las mujeres, sobre todo si se asocia al éxito personal y/o social.

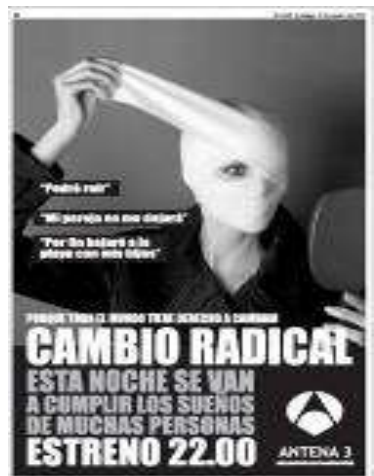

Fuentes: (OIM, 2007: 37)

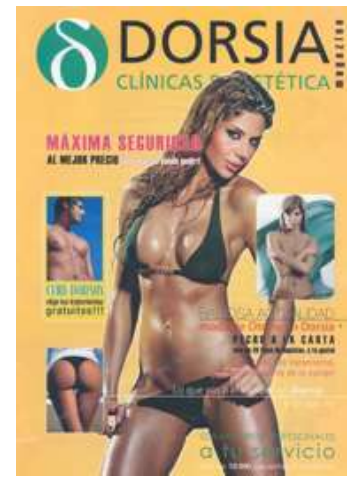

(OIM, 2007: 27)

Anuncio del programa Cambio Radical, de Antena 3 (2007) en el que la cirugía estética permite reír, conservar la pareja y bajar a la playa con los hijos. Sugiere que es la belleza lo que proporciona la felicidad, obviando otros atractivos y capacidades personales y, lo que es peor, los riesgos que conlleva una operación. A su vez, en la imagen del folleto de la clínica Dorsia, se recurre a expresiones como "Pecho a la carta" o "Más de 100 tratamientos para el deleite de tu cuerpo", reflejando como la cirugía estética se convierte en un producto de consumo más.

La presión comercial para parecerse a una imagen física ideal y estandarizada provoca insatisfacción, inseguridad y baja autoestima a las mujeres.

h) Asignar a las mujeres, de manera clara y diferenciada, la responsabilidad exclusiva o principal de cuidados a terceros y al ámbito doméstico, excluyendo o asignando un plano secundario a los hombres en dicha responsabilidad.

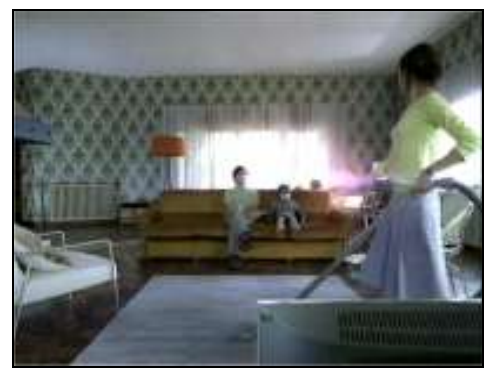

Fuente: (OIM, 2006: 29)
En esta imagen en que la mujer pasa el aspirador mientras padre e hijo permanecen sentados en el sofá mirando, sin participar en las tareas domésticas, queda explícito que esta responsabilidad $u$ obligación es exclusivamente de la madre. 
i) Atribuir capacidades, según el sexo de las personas, para el ejercicio de actividades o categorías profesionales, de forma que se sugiera la falta de aptitud de las mujeres o los hombres para el ejercicio de alguna de ellas.

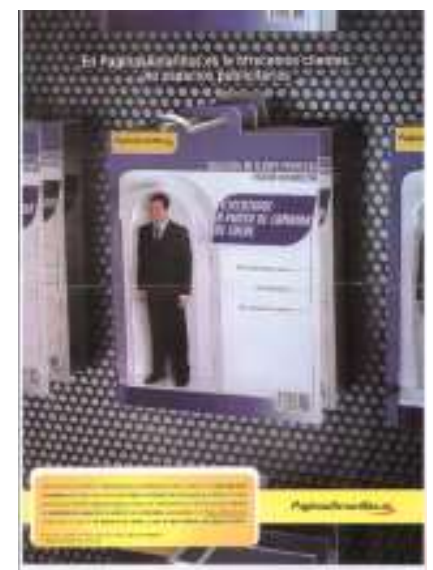

Fuentes: (OIM, 2003: 17)

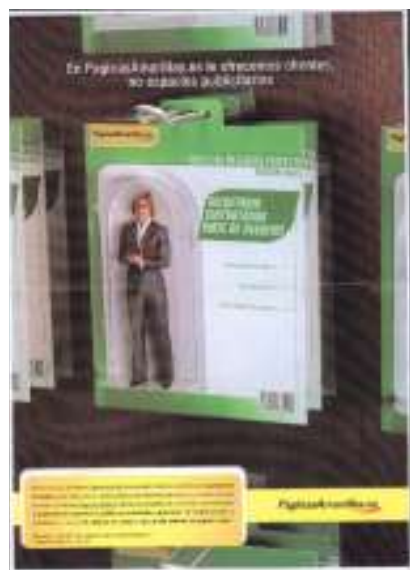

(OIM, 2003: 18)
En esta campaña de Páginas Amarillas se asigna al varón la profesión de "ejecutivo", mientras que la mujer, a pesar de darle una apariencia similar, tiene como ocupación la de secretaria. En ambos casos se recurre a los estereotipos laborales relacionados con el sexo de las personas.

j) Atribuir a los hombres incapacidad para las responsabilidades domésticas o de cuidados y establecer diferencias sobre las opciones o actividades sociales que son adecuadas para hombres o para mujeres. Con especial atención a la infancia y la publicidad de juguetes (OIM, 2008: 48).
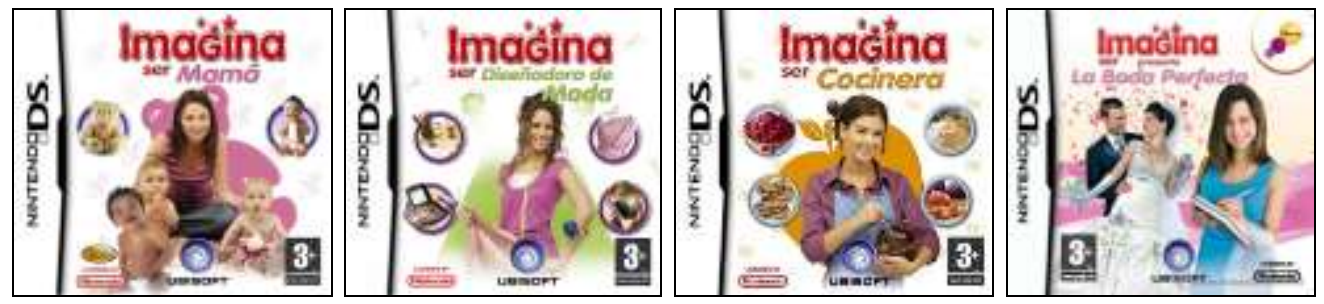

Gama de juegos de consola "Imagina ser...", de la marca UBISOFT, específica para niñas (desde tres años), en la que se aprecia las áreas que el mercado y la publicidad consideran de interés femenino: ser mama, diseñar moda, ser cocinera o la boda perfecta.

No hace falta incluir ejemplos de juegos para niños para saber que no existen contenidos equivalentes para ellos en el mercado (en general más dirigidos a juegos bélicos, de habilidad o deporte, de los que se excluye a las niñas como usuarias). Con esta distinción se refuerza una socialización fuertemente dirigida a mantener los roles de género tradicionales (incluida la oferta profesional).

Es interesante destacar que este caso fue denunciado en Autocontrol, que desestimó la demanda. La queja no incluía la versión "La boda perfecta” y sí otra titulada "Veterinaria". El 
Jurado $^{4}$ aplica las normas 2 (principio de legalidad) y 10 (publicidad discriminatoria) del Código de Conducta Publicitaria y concluye que del contenido de la campaña, a pesar de reconocer que está destinado a un público eminentemente femenino, "no se desprende elemento alguno que explícita o implícitamente afirme, sugiera o dé a entender que las actividades que se muestran en los videojuegos que se están promocionando sean actividades exclusivas o específicas del sexo femenino" y añade que "incluyen un amplio abanico de actividades que abarcan desde tareas domésticas hasta profesionales [...] tal publicidad no transmite mensaje alguno según el cual las niñas deban ver reducido su círculo de actividades, sino al contrario" (Autocontrol, 2008).

El Jurado de Autocontrol ha obviado cualquier valoración basada en el uso de estereotipos de género (que debería contemplarse en el principio de legalidad). Se limita a considerar que no es discriminatoria analizando estrictamente los elementos de la campaña ("no se da a entender que las actividades son exclusivas del sexo femenino") e ignorando que son los factores culturales los que actúan en este sentido sin necesidad de explicitarlo en el mensaje. Basta, como ya se ha dicho, con establecer una comparación con la gama de juegos existentes para niños (incluso del mismo fabricante) para apreciar los criterios estereotipados de asignación de roles de género. Incluso, el Jurado realiza un curioso pronunciamiento enunciando que la campaña amplia el círculo de actividades de las niñas, es decir que da por hecho que las tareas domésticas les corresponden.

k) Confrontar a ambos sexos, resaltando la existencia de ámbitos, actividades o valores propios de hombres y excluyentes para las mujeres.

La campaña de televisión de BURGER KING "Come como un hombre" (OIM, 2006: 16) es un ejemplo de exaltación de la condición de hombre (varón) frente a la identidad femenina. El anuncio empieza con la imagen de un chico que come en un restaurante con una joven (ella muy arreglada, el desaliñado) y que ante un plato minimalista de verduras se levanta y sale del restaurante dirigiéndose hacia una hamburguesería. Se cruza con un grupo de hombres que salen del local con gestos de reafirmación, a los que se van uniendo otros mientras recorren la ciudad, hasta formar un numeroso grupo.

En una imagen se ve una pancarta reivindicativa en la que se lee "Soy un hombre" y el spot se aliña de exagerados rasgos de virilidad. El anuncio termina con un gran grupo volcando un coche por un puente que cae a un camión remolque y un forzudo que lo arrastra con cadenas, al frente una joven le ofrece la hamburguesa en una pala. El texto, una canción que cantan a coro todos los hombres, dice:

\footnotetext{
"Soy un hombre rugiré, estas muy ciego si no lo ves y me muero de hambre.

Mis tripas suenan fatal, ahora mismo iré a buscar un doble whopper.

¡Hombre está genial! ¡Oh si!
}

\footnotetext{
${ }^{4}$ Resolución de la Sección Quinta del Jurado de Autocontrol, de 15 de enero de 2008.
} 
He probado canapés, la soja voy a dejar, ese doble whopper es todo para mí, me hincharé a comer como nadie.

No voy a cambiar.

Voy a tragar esta hamburguesa doble carne, no soy un pringado.

Estoy hambriento, no voy a cambiar"

La voz termina diciendo: "Come como un hombre"

El OIM recibió quejas tanto de hombres como de mujeres sobre esta campaña. Los primeros alegaban que hacía una representación estereotipada y nada real sobre los varones. Todo el anuncio plantea una confrontación entre la idiosincracia femenina y la masculina, más ruda, y la reivindicación de esa identidad varonil frente al influjo y la presión de las mujeres, que supone una amenaza y que les impone cambiar.

1) Recurrir a un lenguaje que de forma clara invisibiliza o excluye a las mujeres, como por ejemplo cuando hay contradicción entre la imagen y el texto en el género aludido.

Un anuncio del Ayuntamiento de Madrid protagonizado por una mujer que, sin embargo, es invisibilizada bajo un sustantivo masculino "Saca el ciudadano que hay en ti" (OIM, 2006: 46). Esta campaña incluía otras versiones protagonizadas por hombres con el mismo lema, por lo que en este caso podía haberse utilizado perfectamente la "ciudadana" en correspondencia con la imagen.
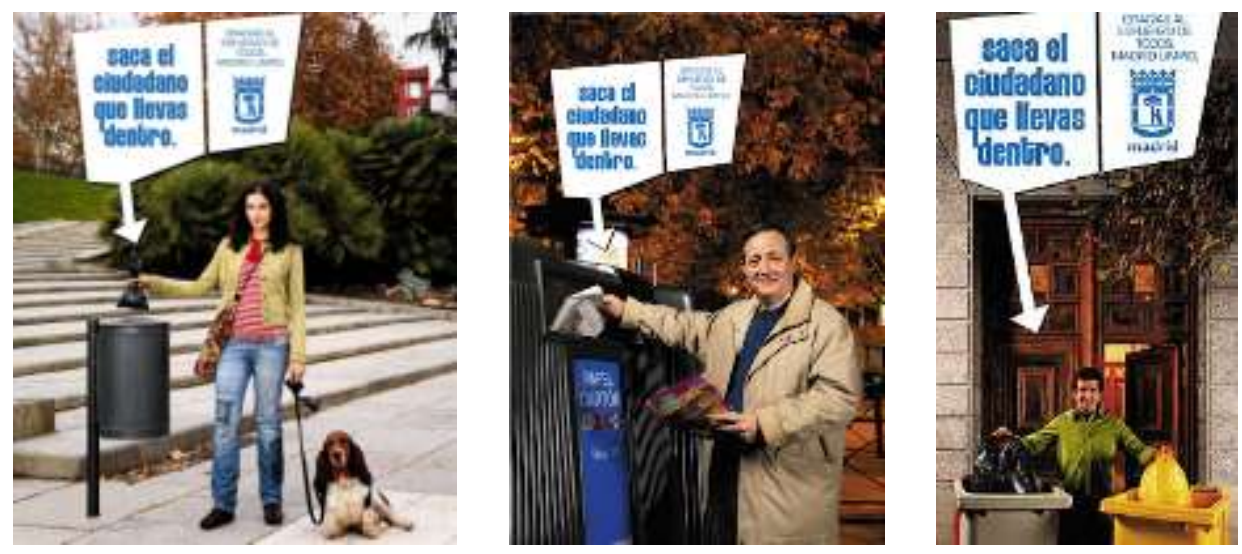

Fuente: (OIM, 2006: 46)

\section{Estrategias que encubren el sexismo publicitario}

En el apartado anterior se han aportado ejemplos en los que se aprecia con claridad el sexismo, pero no siempre aparece tan explícito. La publicidad recurre a diferentes estrategias para aumentar la notoriedad y atraer el interés de la audiencia: 


\subsection{Humor}

Uno de los recursos publicitarios más habituales. Representar de forma cómica las características estereotipadas de las personalidades masculina y femenina suele despertar una sonrisa fácil. Sin embargo, este tipo de publicidad tiene un efecto más perjudicial aún ya que convierte la representación vejatoria en algo positivo, amparando, desdramatizando y restando gravedad a la discriminación y eliminando cualquier posibilidad de lectura crítica. El humor no puede suponer una coartada para denigrar la imagen de las mujeres. Por ejemplo, en una campaña emitida por Frenadol (OIM, 2008: 32) aparece un hombre enfermo al que su mujer le dice que iba a ir a cuidarle una joven canguro pero que como no puede, al final se encargará la suegra.

En el espacio de veinte segundos se reproducen varios estereotipos de género: cuando un hombre está enfermo no puede cuidarse solo, tiene que hacerlo su mujer; las cuidadoras siempre son mujeres; hay una contraposición entre una joven hermosa y una mujer mayor, que altera el estado de ánimo del personaje masculino, y se reitera el tópico negativo de la suegra como una mujer entrometida y difícil de soportar (un alto número de abuelas ejercen como madres suplentes de sus hijas trabajadoras sin que esta figura sea glosada en la publicidad, lo que da una idea del arraigo del tratamiento vejatorio de la imagen de las mujeres).

\subsection{Ambigüedad}

Otro recurso publicitario cada vez más utilizado para crear impacto es exhibir una ambigüedad calculada. Son campañas en las que el mensaje no está definido, sino que queda abierto a distintas interpretaciones por parte de espectadores y espectadoras. Sin embargo, la interpretación más recurrente es la que coincide con los prejuicios de nuestro imaginario social y por tanto la que más refuerza la desigualdad de género. En estos supuestos la valoración del OIM sobre la posible ilicitud resulta más compleja, ya que entra en juego una mayor subjetividad y da lugar a diferentes criterios.

Como ejemplo cabe mencionar el anuncio del vehículo de Alfa Romeo, modelo Guilietta, que se ha emitido en estos últimos meses. En él una voz femenina, combinada con diferentes imágenes del coche en las que también aparece una mujer, va diciendo con tono sugerente "Mirame, tócame, incítame, provócame, sedúceme, contrólame, protégeme, grítame, relájame. Yo soy Giulietta. Si vas a hablar de mí, pruébame”.

Se presupone que la locución se refiere al producto, pero el hecho de que el nombre del vehículo sea femenino y de que se personifique en una mujer se asocia indirectamente con relaciones de género (el anuncio parece dirigido a un público masculino, lo que también constituye una discriminación de las mujeres como potenciales usuarias). Esta representación no solo redunda en estereotipos (protégeme) sino que normaliza comportamientos agresivos (contrólame, grítame) hacia las mujeres. 


\subsection{Direcciones contrapuestas}

Una tercera modalidad de anuncios que dificulta el análisis y la valoración de su contenido son aquellos en los que se presentan dos direcciones contrapuestas: por un lado, en una falsa apariencia de modernidad, se representan modelos de hombre y mujer más acordes con la realidad de nuestros días para, en un plano secundario, sostener las mismas premisas tradicionales sobre responsabilidades, actitudes u ocupaciones.

En este supuesto podemos encuadrar, por ejemplo, todos los que se dirigen a un prototipo de mujer activa, decidida, independiente, empoderada, para después venderle un producto que la hará más bella, más delgada y más joven o le dará la capacidad de abarcar con energía y sin desfallecer todas sus obligaciones, las laborales y las familiares. Los anuncios en los que se halaga la figura de la "superwoman" son cada vez más frecuentes y en ninguno de ellos se reserva un espacio para la corresponsabilidad masculina. Se crea un nuevo modelo de mujer pero sujeta a la doble jornada de siempre.

El caso inverso es el de aquellos anuncios que destacan la participación de los padres en el cuidado de los hijos e hijas pero finalizan resaltando que son "hombres" y, por tanto, se dedican a cosas propias de hombres. Valga como referencia el último anuncio de Renault Scenic, en el que aparecen dos grupos de varias personas practicando paracaidismo: el primero viste de color oscuro y posteriormente se ve que son hombres, y el segundo viste colores vistosos, verde, naranja, amarillo y rosa, y destaca por su gran habilidad.

Al final del spot se observa que el segundo grupo corresponde a un padre con un hijo y dos hijas menores (la más pequeña es la que viste el equipo rosa, que también lleva un osito de peluche) y que se montan en el vehículo promocionado. En la última secuencia, tanto impreso como en locución, se aclara: "Son padres, pero son hombres".

La interpretación tiene aspectos positivos: un padre que cuida de sus hijos/as y las dos niñas que practican, con gran destreza, la misma actividad que ellos. Pero también tiene una lectura sexista, más allá del código de colores de la vestimenta, y es que asocia el deporte y la aventura con los varones, descartando implícitamente que también puedan realizar este tipo de prácticas con la madre.

\subsection{Animación}

Por último, hay campañas en las que se recurre a personajes de animación, humanos o de animales, para representar un orden tradicional que ya no suele utilizarse con personajes reales; en ellos se acentúa la asignación de roles patriarcales en los que la figura femenina se equipara a la de una clásica ama de casa cuya única función y objetivos es cuidar de su hogar, pero que con esta caracterización el enfoque sexista aparece "suavizado".

Esto ocurre en la campaña del ambientador doméstico de Airwick (OIM, 2007: 29) en la que un pulpo hembra realiza simultáneamente, con cada tentáculo, distintas tareas domésticas (planchar, regar o pasar el aspirador) mientras nos relata con voz muy dulce que "...cuidar de 
mi casa no es fácil...", alabando las características del producto que la ayudaban a relajarse y desconectar “...aunque solo sea durante un rato...”, coincidiendo está última frase con el llanto de una criatura que esta a su lado en una cuna. La locución final expresaba “...me siento bien en casa...".

En este apartado puede enmarcarse también la campaña on-line de viajes Iberia, titulada Bebé en Cuba (OIM, 2007:31), en la que aparecía en formato de dibujos animados un bebé que ganaba un viaje y posteriormente aparecía acompañado de dos jóvenes y atractivas mulatas que le proporcionaban cuidados, incluyendo una escena en que una de las mulatas le daba un masaje mientras la otra le abanicaba; el sonido era un varón adulto cantando una canción.

El OIM atendió las quejas que exponían que presentaba numerosos tópicos sobre mujeres relacionados con viajes a otros países, que atentan contra su dignidad ["las coloca al servicio de turistas para bailarles, darles masajes, abanicarles y proporcionarles placeres" (Ibídem)]. O el anuncio de prensa de Alitalia cuya imagen, a modo de ilustración de comic, presentaba a un hombre de rasgos occidentales acompañado por una joven oriental con el siguiente lema "Tener un rollito en primavera está a 87.000 pesetas", el texto redundaba en esta intencionalidad relativa al turismo sexual con la frase "Disfruta de lo prohibido en Banghok, Hong-kong, Bombay o Pekín" (OIM, 2000: 16).

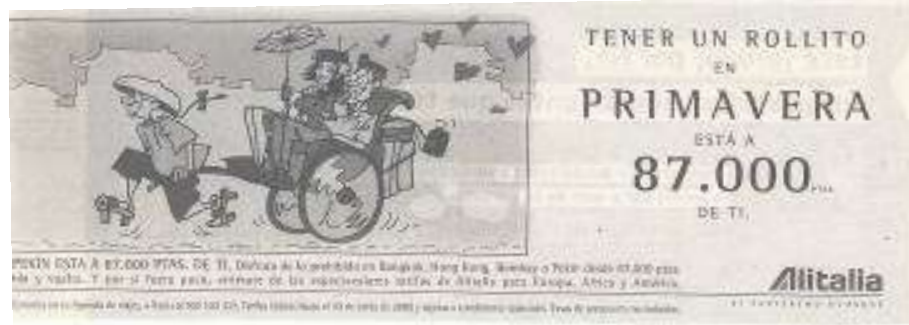

Afortunadamente este tipo de publicidad que no solo denigra a las mujeres, sino que incentiva una forma de violencia de género, es excepcional. También se caracteriza por tener una ambigüedad intencionada que minimiza la gravedad de su contenido.

\subsection{Sexo y erotismo}

Que el "sexo vende" está escrito en casi todos los manuales publicitarios. La discriminación reside en la forma en que se vende ese sexo: el cuerpo femenino como objeto pasivo al que recurre el hombre para obtener placer, un objeto disponible, de libre acceso, que se puede adquirir o disfrutar sin que la sexualidad de las mujeres tenga su propio espacio. El conflicto, en este caso, se presenta a través del discurso de la moralidad, que lleva a interpretar las actuaciones del OIM como una censura más relacionada con el rechazo al desnudo que con el derecho de las mujeres a no ser "cosificadas". 
Nuestra sociedad tiene todavía un profundo reflejo contra cualquier intento de limitar la libertad sexual, producto de décadas de represión. El trabajo pedagógico del OIM se intensifica en esta materia, y hay que aclarar que ninguna campaña en la que el sexo o el erotismo haya sido presentado desde posiciones de igualdad entre mujer y hombre (la publicidad solo suele dar cabida a la heterosexualidad) ha sido denunciada desde el Observatorio, por mucho desnudo que aparezca o muy explícita que sea desde el punto de vista sexual.

El trabajo del OIM consiste en analizar cada pieza, imagen por imagen o palabra por palabra, para determinar los elementos que pueden ser discriminatorios, se presenten como se presenten. Asimismo, para iniciar una actuación se tiene en cuenta el grado de estereotipia y su relación con la realidad de las mujeres, no basta con representar a una mujer asumiendo las responsabilidades domésticas sino que se tiene en cuenta tanto el relato del anuncio como el contexto social.

Es decir, que un anuncio sobre un producto para la merienda de los niños y niñas sea protagonizado por una mujer/madre puede no generar rechazo porque es algo cotidiano en la mayoría de hogares familiares y, aunque se reconoce que reproduce estereotipos de género, no puede clasificarse como publicidad ilícita si no hay un tratamiento vejatorio.

El efecto discriminatorio se produce cuando "todos" los anuncios sobre productos para la merienda son protagonizados por mujeres, pero la Ley de Publicidad esta hecha para aplicarla sobre piezas concretas no sobre tendencias o estrategias de comunicación. Sin embargo, si en ese mismo anuncio la madre prepara la merienda (o pasa el aspirador como en el ejemplo incluido en el apartado anterior) mientras el padre no solo no participa sino que claramente se le desvincula de esas tareas, el incumplimiento de la legislación en cuanto a la reproducción de roles estereotipados es más que evidente.

Un efecto similar se produce si hablamos del uso del cuerpo o partes del mismo como mero objeto desvinculado del producto que se pretende promocionar. A pesar de que esta formulación ha permitido, como ya se ha expuesto, clarificar el carácter discriminatorio de muchas campañas sigue quedando un "territorio incierto" que dificulta la clasificación de una amplia gama de anuncios como ilícitos: campañas de productos para adelgazar, de perfumes o productos de higiene, de depilación, de ropa interior o bañadores, de tratamientos estéticos, etc. En ellos la representación como objeto sexual depende de la utilización que se haga del cuerpo, si se acentúa la exhibición o se convierte a la mujer en el objeto real de la oferta, pero, hay que reconocerlo, no es tarea fácil marcar la línea divisoria.

\section{De la publicidad a los medios de comunicación}

Desde el año 1995 hasta diciembre de 2011, el OIM ha recibido más de 7.000 denuncias, referidas a un total de 2.606 contenidos, con la siguiente distribución: 
Grafico 4: \% de quejas por sector

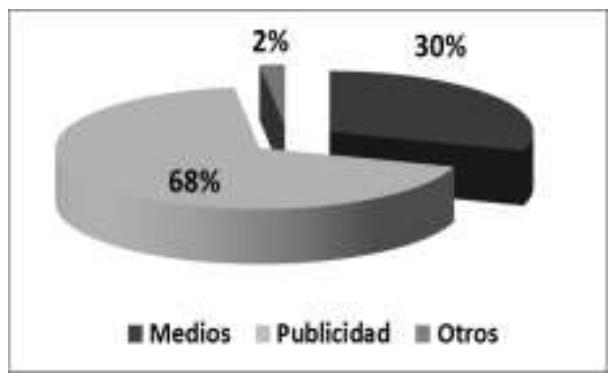

Grafico 5: $N^{o}$ de contenidos denunciados por sector

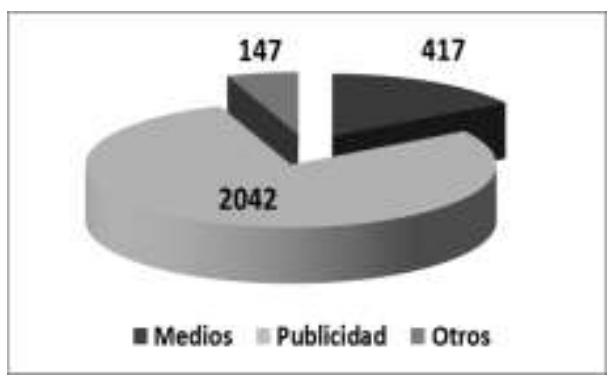

Elaboración propia

El apartado "Otros" comprende quejas por canciones, libros y cuentos, actividades culturales, espacios web, etc. que no están comprendidos en los otros dos. Hasta el año 2007, el porcentaje de quejas sobre los medios de comunicación estaba entre el 5\% y el 13\% (media anual del 8\%), pero en estos últimos cuatro años la media anual ha ascendido al 47,5\%, llegando en el año 2010 a representar el $85 \%$ del total de las quejas. Este alto porcentaje de 2010 se debió a la emisión de una serie de Telecinco, "Inocentes"5 que acumuló 1.591 denuncias por frivolizar sobre la trata y la explotación sexual de las mujeres.

Esta evolución de las quejas parece reflejar dos situaciones: una, que efectivamente la publicidad, sobre todo la de las grandes marcas que son las que más invierten, se ha vuelto más cuidadosa a lo largo del tiempo y otra, que la ciudadanía ha dirigido su mirada crítica a los medios de comunicación, que comparten con la primera, tanto en su vertiente informativa (en menor medida) como en la de entretenimiento, una representación completamente estereotipada de las mujeres.

Con la extensión de la denominada "telebasura" en un afán por aglutinar mayor audiencia, y con los reality show como eje de la programación, la cosificación y vejación de las mujeres se ha incrementado escandalosamente. El punto álgido lo supuso la protesta generalizada hacia un participante de las primeras ediciones de Gran Hermano por sus actitudes agresivas hacia una compañera. Finalmente fue expulsado del programa aunque, lamentablemente, conservó su atractivo mediático. Con la persistencia de estos programas, junto con los de pseudodebate protagonizados por mal llamados periodistas y famosos/as como Sálvame o La Noria y algunos programas de humor, como el Hormiguero, las televisiones han demostrado una absoluta falta de responsabilidad social en materia de igualdad de género.

En los últimos 6 años, las quejas por programas de televisión ascienden a 2.090, lo que representa el $37,9 \%$ del total en el mismo periodo, y el 76,5\% de las relativas a medios de comunicación:

\footnotetext{
${ }^{5}$ Serie de 2 capítulos sobre el secuestro y explotación sexual de tres chicas por una mafia. Sin que esté basada en el caso real, hace una referencia al suceso del secuestro y asesinato de las tres jóvenes de Alcasser.
} 
Grafico 6: Porcentaje de quejas sobre programación de televisión

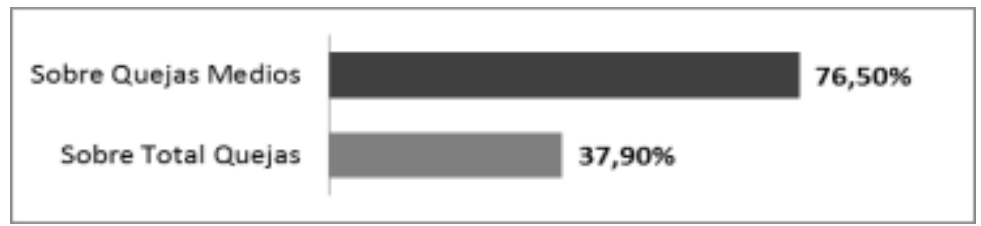

Elaboración propia

Por cadenas de televisión los resultados son:

\begin{tabular}{|c|c|c|c|c|c|c|}
\hline & TVE -1 & Antena 3 & Cuatro & Telecinco & Sexta & Resto \\
\hline $\mathbf{N}^{\mathbf{0}}$ de quejas programación & 40 & 38 & 84 & 1832 & 45 & 51 \\
\hline Porcentaje & $1,9 \%$ & $1,8 \%$ & $4 \%$ & $87,6 \%$ & $2,1 \%$ & 2,45 \\
\hline
\end{tabular}

El caso de la mencionada serie Inocentes, de Telecinco, evidentemente condiciona el resultado estadístico por la gran acumulación de denuncias en un solo programa. Con el fin de reflejar una situación menos excepcional, puede realizarse la comparación sin contar con estas 1591 quejas. El resultado obtenido es el siguiente:

Grafico 7: Porcentaje de quejas según cadenas de TV

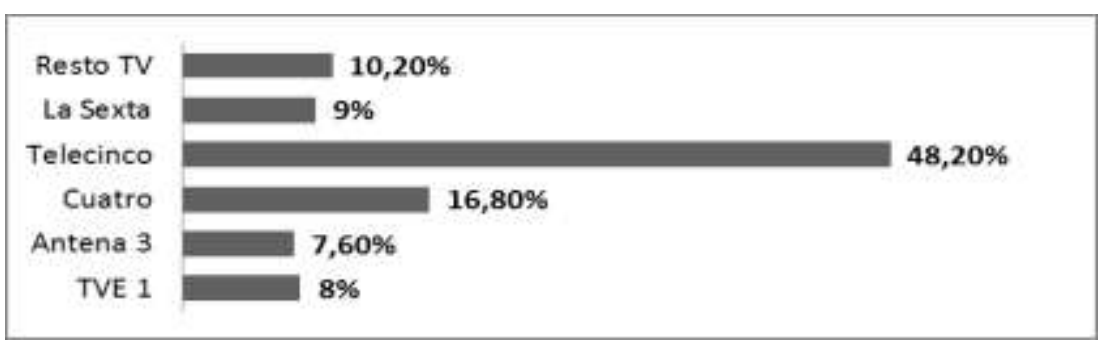

Elaboración propia

Telecinco sigue siendo la cadena que más protestas acumula, casi el 50\%, seguida de Cuatro (con anterioridad a la fusión). Hay que tener en cuenta, no obstante, otros aspectos más allá de lo meramente cuantitativo, como por ejemplo los índices de audiencia: las cadenas Cuatro y la Sexta tienen aproximadamente la mitad de audiencia que TVE, Antena 3 y Telecinco, por lo que, en proporción, el peso de las quejas, sobre todo en Cuatro, pone de manifiesto una mayor presencia de sexismo.

Otro factor a tener en cuenta es la gravedad, habitualidad y persistencia de los contenidos, en este caso hay que romper una lanza a favor de TVE, porque aunque acumula el $8 \%$ de las quejas suelen referirse a cuestiones aisladas o puntuales (como comentarios esporádicos de algún colaborador) no a bloques de programación como ocurre en las cadenas 
privadas; en general el nivel de exigencia de la audiencia con la televisión pública es más estricto, al igual que el del propio OIM.

Entre los programas que más rechazo han generado en estos últimos 6 años están los reality shows, con 204 quejas en total (el 40,8\% sobre las quejas de programación de televisión) referidas a 18 programas. Los más protestados han sido:

- De Telecinco, I Love Escassi $(29,4 \%)$ con solo una temporada; Gran Hermano $(19,6 \%)$, repartidas en las seis temporadas; Mujeres y Hombres $(7,8 \%)$, en cuatro temporadas. En el primero y el tercero es la propia concepción del programa lo que promueve el despliegue de estereotipos vejatorios sobre las mujeres.

- De la Sexta, Generación Nini (12,7\%), este programa generó todas las quejas por una secuencia en la que dos concursantes restregaban sus órganos genitales por el cuerpo de una compañera contra su voluntad, en lo que se calificó como una situación de abusos sexuales.

- De Cuatro, Supermodelo (8,3\%) y Granjero busca esposa (5,3\%), en dos y tres temporadas, respectivamente. En el primero se criticó no solo que el programa estuviera protagonizado solo por mujeres (la profesión de modelo no es exclusivamente femenina) sino que se les daba un trato humillante y con una presión excesiva. En el segundo, se resaltó que se redundaba en el fomento de estereotipos domésticos y de género y se menospreciaba a las mujeres.

Grafico 8: Porcentaje de quejas por programas de TV

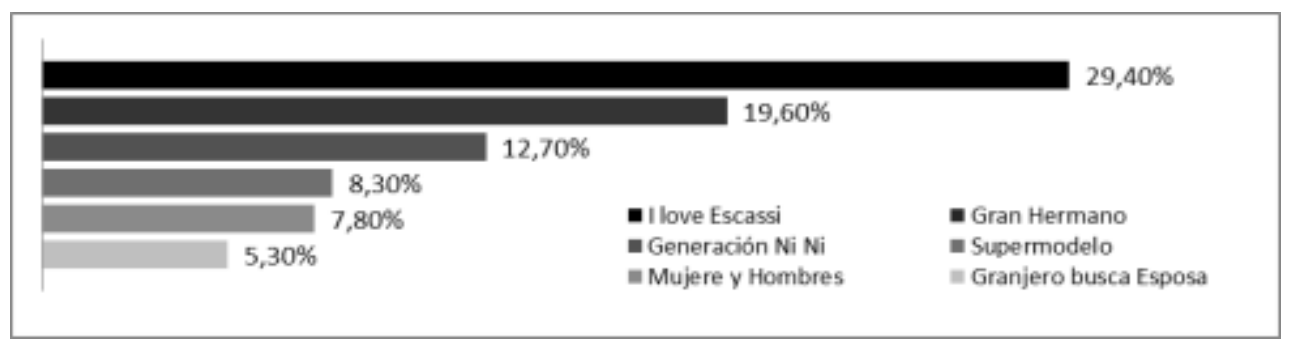

Elaboración propia

En los programas de telerealidad abundan las actitudes más asociadas a los roles de género, se refuerzan los comportamientos clásicos de masculinidad y feminidad y, entre ellos, aparecen los estereotipos más negativos sobre las mujeres, como por ejemplo la rivalidad entre ellas, especialmente en un contexto de conquista y seducción.

Las propias participantes seleccionadas se prestan a todo tipo de situaciones que redundan en una imagen vejatoria en lo que parece una estrategia premeditada por las propias productoras. 


\section{Machismo y apología de la violencia de género en la red}

Internet es un espacio donde parece concentrarse la representación más vejatoria y degradante para las mujeres, llegando a la apología impune de la violencia de género. Desde la existencia de páginas destinadas a la misoginia más agresiva hasta foros en los que se vierten las opiniones más ofensivas y los comentarios más machistas, pasando por la intensificación de la cosificación y la representación de las mujeres como un objeto sexual. Las características de Internet dificultan tanto el seguimiento como la actuación ante los contenidos denunciados, en muchas ocasiones amparados en el anonimato o ubicados en otros países.

Considerado como un medio de medios, las quejas adquieren una amplitud que desborda los objetivos iniciales del Observatorio, ya que se refieren por igual a publicidad y a medios de comunicación digitales, como a portales, web de empresas o de colectivos o sites personales. Algunas denuncias se refieren a piezas, como videos, que circulan por la red sin autoría específica y que permanecen en el tiempo en lo que se conoce como viralidad, por lo que no pueden asociarse a un emisor concreto.

Mención aparte merecen todas las páginas web sobre prostitución o pornografía que van más allá de las competencias asignadas al OIM. A pesar de esta circunstancia, se reciben todas las quejas y analiza el contenido determinando posteriormente la capacidad de actuar. Desde 1994 el número de protestas se ha ido incrementando de forma paralela al crecimiento del número de usuarios y usuarias de la red. Entre 1994 y 1999 se recibieron 11 quejas sobre Internet, entre 2000 y 2005, 77 y en los últimos 6 años han ascendido a 539. En el pasado año, 2011, Internet es el segundo medio más denunciado, con 178 quejas (27,3\% del total), tras televisión, con 200.

El avance que se aprecia en el tratamiento publicitario de la imagen de las mujeres, incluso el aumento de sensibilidad en algunos medios de comunicación, contrasta con el exceso, en cantidad y en gravedad, de machismo y sexismo que invade Internet.

Algunos casos registrados en el Observatorio han sido: los videos de Youtube "Se cumple un año de la detención de Carcaño. Marta de Castillo se buscó su propia muerte por putilla" (en el que, aparte de incluir toda clase de comentarios vejatorios no solo hacia la víctima, sino también hacia su familia, se culpabiliza del asesinato a la propia víctima, de acuerdo con las pautas patriarcales en la violencia de género) e "Instrucciones exactas de cómo maltratar a una mujer" (se explica paso a paso como efectuar una agaresión); el foro "Ministerio de equilibrio" (en el se insulta y menosprecia a asociaciones, instituciones y responsables de organismos públicos y se ofrecen links a páginas como Feminazis, Hembristas, Misándricas o Andrófobas, todas del mismo tenor), o el Blog "Odio a las mujeres" (se defiende y se incita al maltrato a las mujeres). 


\section{Un balance positivo}

El balance que dejan casi 18 años de trabajo del Observatorio de la Imagen del Instituto de la Mujer puede considerarse positivo. Se ha contribuido a cambiar, en el sector profesional y en el propio público destinatario, la percepción sobre lo que es o no aceptable en la representación de las mujeres. Tanto las grandes marcas como las grandes agencias cuidan más la utilización de la imagen femenina. Sin pretender atribuirle en exclusiva un mérito que pertenece al trabajo de muchas personas, entidades e instituciones públicas y privadas, hay que afirmar, y así lo reconocen muchos y muchas publicistas, que en España no podrían emitirse campañas que se emiten en otros países, tanto europeos como americanos, porque serían objeto de amplio rechazo.

En estos 18 años, el Instituto de la Mujer se ha dirigido a los emisores (anunciantes o medios de comunicación) solicitando la modificación o cese de sus contenidos en 265 ocasiones, una media de 14,5 anual, siendo el año 2010, con 31, en el que más requerimientos se han producido.

A partir del año 2006 (tras la aprobación de la Ley de Violencia de Género) y teniendo en cuenta la evolución de la creatividad y lo expuesto sobre las estrategias que contribuyen a encubrir el sexismo, se dirigen también recomendaciones sobre cómo puede mejorarse el tratamiento de la imagen de las mujeres: entre 2006 y 2011 se remitieron 63 escritos de recomendaciones, una media de 10,5 anuales. En total son 328 demandas sobre los 2.606 contenidos denunciados, lo que representa el $12,5 \%$. Este bajo porcentaje de requerimientos no se debe tanto a que los contenidos denunciados no se consideren estereotipados o discriminatorios, sino a que se actúa expresamente en los casos de mayor gravedad, con el fin de favorecer la percepción de la ilicitud de la publicidad según la legislación vigente.

Tomando el periodo 2006-2011 como referencia, el porcentaje de solicitudes de cese/modificación y de recomendaciones sobre los escritos remitidos es el siguiente:

Grafico 9: Porcentaje de solicitudes de cese/modificación y recomendaciones sobre total de escritos

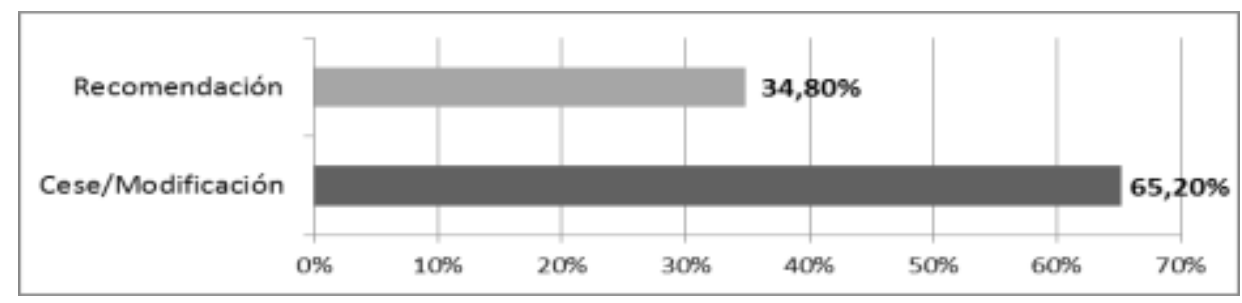

Elaboración propia

Tras los requerimientos de cese/modificación o los escritos de recomendaciones, se hacen seguimientos del resultado a partir de las respuestas que se reciben o a través de herramientas como Infoadex, que permiten detectar si el contenido ha sido modificado o ha dejado de emitirse. Pero hay casos en que ese seguimiento no es posible por ser campañas o 
contenidos de los medios de carácter muy puntual (sin continuidad, como por ejemplo publicidad de eventos concretos, artículos o reportajes específicos, comentarios en un programa), de ámbito local y/o en soportes no accesibles sin la aportación de la ciudadanía (publicidad exterior, revistas especializadas o corporativas, catálogos, folletos, expositores de locales, carteles, etc.).

Esta circunstancia impide obtener una evaluación precisa de la efectividad de las actuaciones llevadas a cabo. No obstante, en un análisis hecho sobre las 192 realizadas entre los años 1999 y 2009 se obtienen los siguientes resultados:

- 23 de ellas (11,9\% del total) responden a lo que hemos denominado casos puntuales.

- Se recibe respuesta en 100 ocasiones (52\% del total), de las que el 77\% resultan positivas porque se acepta retirar o modificar el contenido o, en caso de que haya finalizado, adoptar medidas para evitar el tratamiento sexista en posteriores acciones de comunicación. El restante $23 \%$ rechaza la interpretación de sexismo remitida desde el Observatorio (aún así, en algunos de estos casos se observó posteriormente que la campaña se había modificado o que el tono de las siguientes mejoraba).

- En 69 casos $(35,9 \%)$ no se recibe ninguna respuesta. El seguimiento de los mismos permite conocer que 41 de ellas $(59,4 \%)$ han desaparecido o se han modificado y 28 $(40,5 \%)$ han continuado emitiéndose al menos durante un tiempo.

Grafico 10: \% casos según seguimiento

Grafico 11: \% casos según respuesta recibida
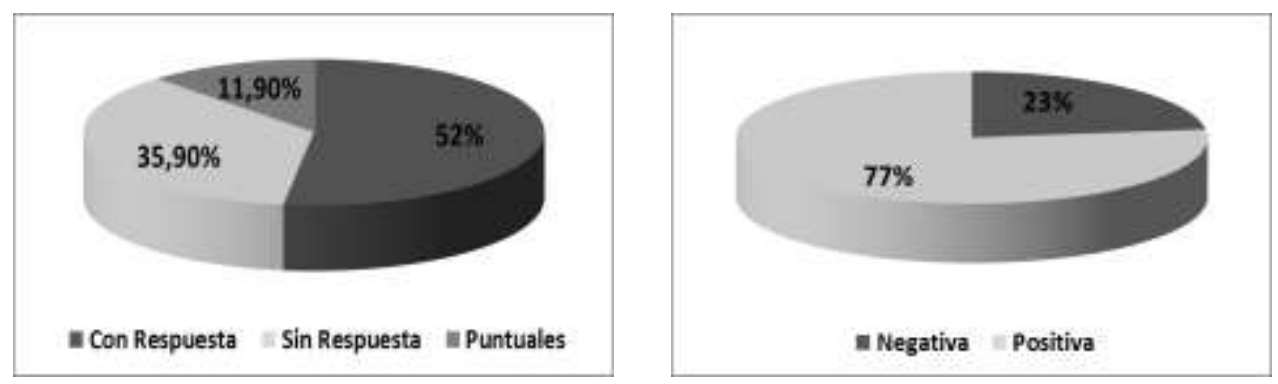

Elaboración propia

Grafico 12: Porcentaje resultados seguimiento de casos sin respuesta

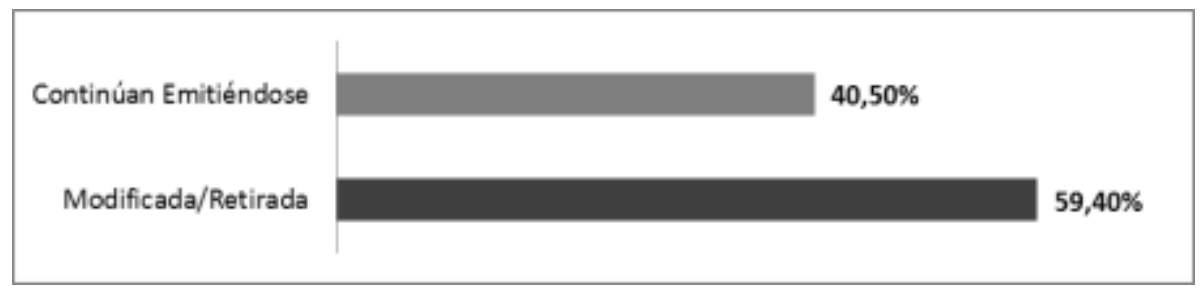

Elaboración propia 
Tomando de las 192 actuaciones únicamente las 169 sobre las que se ha podido realizar el seguimiento, y agrupando los resultados considerados positivos, tanto por la respuesta recibida (77) como por el control propio (41), se alcanza un 70,5\% de efectividad.

Grafico 13: Porcentaje total de resultados

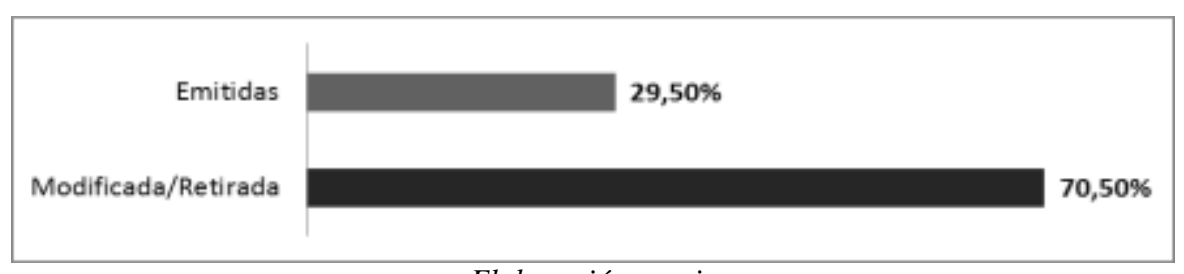

Elaboración propia

A pesar de estos datos no puede determinarse categóricamente el grado de efectividad de las actuaciones, ya que hay campañas que pueden ser reemitidas tiempo después (y que pueden, o no, volver a ser detectadas) o que se modifican pero presentan otra forma de sexismo. No obstante, con el fin de obtener otro indicador que dé una idea de los resultados obtenidos se han revisado 257 emisores:

- $113(43,9 \%)$ presentan quejas en distintos años por campañas diferentes, de ellos 40 han recibido un requerimiento o recomendaciones en algún momento.

- $20(7,7 \%)$ presentas quejas en distintos años por la misma campaña, de ellos 6 la repiten después de recibir el escrito del OIM

- 18 empresas ha recibido más de un escrito por distintas campañas.

De estos datos concluimos que el porcentaje de anunciantes, sobre la muestra analizada, que reiteran la misma campaña tras recibir escrito del OIM es del 2,3\% y el porcentaje de anunciantes que han recibido más de una comunicación es del $7 \%$.

Entre las compañías que más insisten en reproducir contenidos sexistas esta UNILEVER, con las campañas del desodorante AXE: entre 1999 y 2009 ha recibido casi 100 quejas ("Márcales el camino" fue la versión que más rechazo despertó), en todos ellos con piezas que reproducen el mismo planteamiento: el producto genera un efecto mágico ("el efecto AXE") que permite al usuario del desodorante manejar fácilmente a las mujeres, que son presentadas como seres carentes de voluntad o como objeto sexual.

Desde el OIM se han remitido tres requerimientos (en 1999, 2007 y 2010) cada uno por una versión, esas campañas no se han repetido, pero la estrategia ha seguido siendo la misma y con el mismo "efecto discriminatorio", en una demostración de irresponsabilidad por parte de la marca, que prima sus intereses comerciales por encima del derecho de las mujeres a ser tratadas con dignidad. 
La regla de actuación del OIM es reclamar directamente al anunciante, pero en aquellas ocasiones en que el contenido es especialmente grave o tiene una elevada repercusión, se ha procedido a realizar una declaración pública de rechazo. Estas denuncias públicas efectuadas por el Instituto de la Mujer han contribuido a promover un debate social y una toma de conciencia que ha permitido incrementar la reflexión social sobre la discriminación en materia de comunicación.

Casos como la campaña de la marca Doce y Gabbana (OIM, 2007: 14) en la que se representaba una situación con referencias a un acto de violación, o de la compañía aérea de bajo coste Ryan Air (Ibídem: 24) que publicó un calendario erótico protagonizado por azafatas, han alcanzado repercusión internacional, provocando, en el primer caso, la retirada del anuncio no solo en España sino en todo el mundo.

\section{Conclusiones}

La discriminación de las mujeres a través de la publicidad y los medios de comunicación es un hecho demostrado y reconocido, que se produce fundamentalmente por la reiteración de estereotipos de género como la asignación exclusiva o prioritaria del rol doméstico tradicional, la cosificación y utilización de las mujeres como objeto sexual, la exaltación de la belleza asociada a modelos idealizados y alejados de la realidad o la adjudicación de cualidades y capacidades diferenciadas para hombres y para mujeres.

La necesidad de erradicar estos estereotipos y fomentar un tratamiento igualitario en el ámbito de la comunicación está regulado por distinta normativa nacional e internacional, con el objetivo de modificar las actitudes y comportamientos sociales que permitan avanzar hacia la igualdad real.

El Observatorio de la Imagen de las Mujeres es una herramienta de participación ciudadana que ejerce funciones de control y seguimiento de la discriminación por razón de sexo en la publicidad y los medios, contribuyendo a cumplir los objetivos establecidos en la legislación vigente.

A lo largo de este tiempo se ha observado una mejora en el tratamiento publicitario de la imagen de las mujeres, especialmente por parte de las grandes compañías, que han asumido paulatinamente los cambios sociales de la situación de las mujeres. Las campañas más denigrantes son emitidas, en general, por pequeños anunciantes locales y a través de soportes de menor alcance. No obstante, y a pesar del incremento general de la sensibilidad del sector y del rechazo por parte de la ciudadanía, la publicidad sigue recurriendo a una representación desigual introduciendo nuevos estereotipos o modificando los tradicionales hacia formas menos evidentes. 
Se ha reducido, por ejemplo, la imagen de una mujer aislada en su hogar, ocupada y preocupada únicamente por la función de cuidados y se ha sustituido por otra más moderna e independiente pero igualmente vinculada prioritariamente al ámbito doméstico. Se la relaciona con la actividad laboral, pero generalmente asociada a profesiones feminizadas o categorías de menor jerarquía que las de los hombres, a quienes se siguen reservando ámbitos específicos. Se ha intensificado considerablemente la presión sobre el aspecto físico, presentándolo como la principal cualidad femenina y asociándolo al éxito personal, social y profesional, con la aparición de una amplia oferta de productos y tratamientos, tanto cosméticos como quirúrgicos, que resuelven las "deficiencias" corporales, que son presentadas como problemas de salud y no estéticos (según el modelo de referencia).

También ha cambiado la representación de los hombres que, por ejemplo, están más relacionados ahora con su rol de padres, pero se les sigue reservando la jerarquía familiar. Se les invita al cuidado de la apariencia física, pero con un mensaje y un tono diferente al que se utiliza para las mujeres. Ellos siguen conservando la primacía en valores como la experiencia, la autoridad, la capacidad intelectual o el gusto por la aventura y el riesgo. La publicidad es mucho más abierta y explícita en materia de sexualidad que hace veinte o treinta años, pero sigue presentando a los hombres como los sujetos de la relación y a las mujeres como los objetos.

En los últimos años, el rechazo al sexismo publicitario se ha trasladado de forma evidente a los medios de comunicación, especialmente hacia la televisión, coincidiendo con la expansión de programas de telerrealidad donde las mujeres reciben a menudo un trato vejatorio y se atenta contra su dignidad tanto verbalmente como mediante las caracterizaciones y actitudes que deben asumir. En el panorama de los medios, Internet ha ido adquiriendo protagonismo, pero también se ha convertido en el espacio donde se presentan los contenidos más machistas y agresivos.

El OIM ha desarrollado, desde su creación en 1994, una amplia actividad dirigiéndose a los emisores de los contenidos sexistas, en algunas ocasiones de forma pública, tanto con requerimientos para el cese o la modificación de las campañas como con recomendaciones para mejorar el tratamiento de la imagen de las mujeres. Su trabajo se ha difundido mediante la elaboración de informes anuales, que se ponen a disposición del público en la página web del Instituto de la Mujer y que ha servido de referencia tanto a personas expertas como a quienes se iniciaban en el estudio de la representación pública de las mujeres.

La aprobación de las leyes de Violencia de Género (2004) y de Igualdad Efectiva (2007) han constituido para el Observatorio un importante refuerzo en el ejercicio de sus funciones, ya que han permitido clarificar el concepto legal del sexismo y definir la obligatoriedad de anunciantes y medios de respetar los derechos de las mujeres. 


\section{BIBLIOGRAFÍA}

- AUTOCONTROL - Asociación para la Autorregulación de la Comunicación Comercial (2008): "Resolución Sección 5 a de 15/01/2008: Autocontrol a instancia de la Secretaría de Estado de Telecomunicaciones y para la Sociedad de la Información (SETSI) vs. Ubisoft, S.A., ('Imagina ser')", [en línea] Disponible en: http://www.autocontrol.es/panelcontrol/web/paghtml/buscar.asp?Page=42\&tabla=1 [13/12/2011].

- España (2009): "Modificación de la Ley 34/1988, de 11 de noviembre, General de Publicidad". En BOE núm. 315, pp. 112039-112060.

- Núñez Domínguez, Trinidad y Loscertales Abril, Felicidad (coord.) (2009): Las mujeres y los medios de comunicación. Una mirada de veinte años (1989-2009). Sevilla: Instituto Andaluz de la Mujer.

- OIM - Observatorio de Imagen de las Mujeres (1994) [en línea] Disponible en: http://www.inmujer.gob.es/ss/Satellite?c=Page\&cid=1264005600756\&language=cas ES\&pagenam e=InstitutoMujer\%2FPage\%2FIMUJ Generico [04/12/2011].

. (2006): Informe anual 2006. Instituto de la Mujer

. (2007): Informe anual 2007. Instituto de la Mujer.

. (2008): Informe anual 2008. Instituto de la Mujer.

. (2009): Informe anual 2009. Instituto de la Mujer.

- OPS - Observatorio de la Publicidad Sexista (2000): Informe anual OPS 2000. Instituto de la Mujer.

- Parlamento Europeo (1987): "Resolución sobre la presentación y posición de la mujer en los medios de comunicación de masas". En DO C 305 de 16.11.1987, [en línea] Disponible en: http://eur-lex.europa.eu/Notice.do?val=132040:cs\&lang=es\&list=132040:cs, 134261:cs, 1342 63:cs,\%20134238:cs,\&pos=1\&page=1\&nbl=4\&pgs=10\&hwords $=[13 / 12 / 2011]$.

- Parlamento Europeo (1995): "Resolución del Consejo y de los Representantes de los Gobiernos de los Estados miembros, reunidos en el seno del Consejo, de 5 de octubre de 1995, relativa a la lucha contra el racismo y la xenofobia en los ámbitos del empleo y de los asuntos sociales". En DO C 296 de 10.11.1995, [en línea] Disponible en: http://eur-lex.europa.eu/Notice.do?val=207297: cs\&lang=es\&list=207297:cs,310585:cs,307146:cs, 210688:cs, 210687:cs, 210686:cs, 210685:cs, 2106

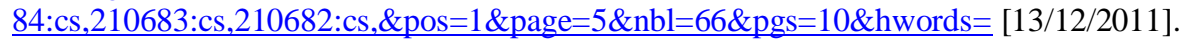

- Parlamento Europeo (2009): "Resolución del Parlamento Europeo, de 3 de septiembre de 2008, sobre el impacto del marketing y la publicidad en la igualdad entre mujeres y hombres (2008/2038(INI))". En DO C 295E de 04.12.2009, [en línea] Disponible en: http://eurlex.europa.eu/Notice.do?val=507904: cs\&lang=es \&list=507904:cs, \&pos=1\&page=1\&nbl=1\&pgs=1 0\&hwords=Impacto\%20del\%20marketing [13/12/2011].

- Parlamento Europeo (1997): "Resolución sobre la discriminación de la mujer en la publicidad". En DO $C \quad 304$ de 6.10.1997, [en línea] Disponible en: http://eurlex.europa.eu/Notice.do?val=\%20319065:cs\&lang=es\&list=507904:cs,319065:cs, \&pos=2\&page=1

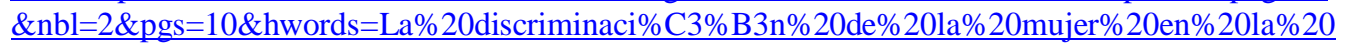
publicidad [13/12/2011].

- Teresa García Nieto y Carlos Lema Devesa (2008): Guía de intervención ante la publicidad sexista. Madrid: Instituto de la Mujer.

- Williams, John E. y Best, Deborah L. (1990). Measuring Sex Stereotypes: A multination study. Newbury Park: Sage. 